\title{
Trusting on the Shoulders of Open Giants? Open Science Increases Trust in Science for the Public and Academics
}

\author{
Hyunjin Song, ${ }^{\text {a }}$ David M. Markowitz, ${ }^{\mathrm{b}}$ \& Samuel HardmanTaylor ${ }^{\mathrm{c}}$ \\ ${ }^{\text {a }}$ Department of Communication, Yonsei University, Seoul, South Korea \\ ${ }^{\mathrm{b}}$ School of Journalism and Communication, University of Oregon, Eugene, OR, USA \\ ${ }^{c}$ Department of Communication, University of Illinois Chicago, Chicago, IL, USA
}

\section{Contact Information:}

\section{Hyunjin Song}

Department of Communication

Yonsei University

50 Yonsei-ro, Seodaemun-gu, Seoul, 03722 South Korea

hyunjinsong@yonsei.ac.kr

David M. Markowitz

School of Journalism and Communication

University of Oregon

153 Franklin Blvd

Eugene, OR 97403 USA

dmark@uoregon.edu

Samuel HardmanTaylor

Department of Communication

University of Illinois Chicago

3152A BSB Chicago, IL 60607

samuelht@uic.edu

Forthcoming in Journal of Communication

Open Practices, Disclosure Statement, and Funding Acknowledgement

Materials, data, and analysis code associated with this study have been made publicly available via OSF and can be accessed at https://osf.io/9dfzu/. We disclose that we do not have any conflict of interests. The corresponding author (Hyunjin Song) received funding support from the Yonsei University (Yonsei New Faculty Research Seed Funding Grant).

Correspondence concerning this article should be addressed to Hyunjin Song, Department of Communication, Yonsei University, Seoul, South Korea.hyunjinsong@yonsei.ac.kr 


\begin{abstract}
Researchers often focus on the benefits of adopting open science, yet questions remain whether the general public, as well as academics, value and trust studies consistent with open science compared to studies without open science. In three preregistered experiments (total $N$ $=2,214$ ), we find that the general public perceived open science research and researchers as more credible and trustworthy than non-open science counterparts (Studies 1 and 2). We also explored if open science practices compensated for negative perceptions of privately-funded research versus publicly-funded research (Study 2), although evidence did not support this hypothesis. Finally, Study 3 examined how communication scholars perceive researchers and their work as a function of open science adoption, along with publication outlet (e.g., highprestige vs. low-prestige journals). We observed open science research was perceived more favorably than non-open science research by academics. We discuss implications for the open science movement and public trust in science.
\end{abstract}

Keywords: open science, questionable research practices, trust, epistemic trust 


\section{Trusting on the Shoulders of Open Giants? Open Science Increases Trust in Science for}

\section{the Public and Academics}

The normative ideal that science — and hence the way we, as scientists, perform research — should be transparent and open is hard to dispute. Scientific knowledge production is frequently characterized as a highly collective and cumulative endeavor (Howard, 1991; Kuhn, 1962; Merton, 1957, 1973), and by being transparent and open, any tentative discovery would withstand public scrutiny to be provisionally accepted as scientific knowledge (Resnik, 1998). Indeed, this mantra ascribes how science accumulates a body of knowledge — by "standing on the shoulders of giants" — who lay the intellectual foundations of what we discover today. While history of scientific knowledge production is often characterized by many radical paradigm shifts as described by Kuhn (1970), the very idea that scientific knowledge progression is collective and cumulative in nature, and that scientific knowledge production therefore requires transparency and openness in the process of discovery of relevant evidence, constitutes the essential view of scientific research as we know it today.

However, the validity and reliability of scientific research in many social science fields have become the subjects of intense scrutiny. While some suspect the prevalence of questionable research practices (QRPs: Simmons et al., 2011; also see Matthes et al., 2015), others blame a lack of appropriate collective norms — such as the field-level publication bias for novel and "significant" results (Ioannidis et al., 2014; Keating \& Totzkay, 2019) or limited attempts for conceptual and direct replications (Dienlin et al., 2021; McEwan et al., 2018). In any case, a recent scholarly dialogue, which is broadly named the "open science" movement, calls for systematic reforms in the modus operandi of conducting scientific research. In line with this development, the field of communication research is gradually acknowledging the importance (Dienlin et al., 2021) as well as various barriers and potential pitfalls (Fox et al., 2021; Freilling et al., 2021) of adopting open science research, while 
beginning to empirically assess to where communication - as a field - stand on the issues of QRPs and a lack of open science practices (Bakker et al., 2021; Markowitz et al., 2021).

Although there are many arguments for adopting more open and transparent research practices (Dienlin et al., 2021; Lewis, 2019; Nosek et al., 2015; Open Science Collaboration, 2015), another implicit — and unintended — benefit of adopting more open research practices is its potential for restoring public trust towards science and scientific findings. Often, scholars voice their concerns over the low replicability and the prevalence of QRPs, in that they may lead to a "crisis of confidence" (Pashler \& Wagenmakers, 2012, p. 528). They also worry that the recent replication crisis in many social science fields may fuel public criticism toward scientific research and would increase anti-scientific sentiments (e.g., Anvari \& Lakens, 2019; Ioannidis, 2017; Maxwell et al., 2015; Mede et al., 2020). Although it is unclear whether a similar "replication crisis" exists in communication research (see Keating \& Totzkay, 2019; McEwan et al., 2018), some scholars argue that the field of communication is unlikely to be immune to the problems associated with such crises (e.g., Bakker et al., 2021; Matthes et al., 2015). Nevertheless, those who advocate for more transparent and open practice see the adoption of open science as an opportunity to bolster the credibility and trustworthiness of the scientific findings - thereby rescuing the eroding trust towards science and associated scientists (Dienlin et al., 2021; Grimes et al., 2018; Yarborough, 2014). ${ }^{1}$

Thus, there is a need to investigate the public's engagement with open science practices, and the effect on the perceived trust and credibility of science, as well as towards scientists. Previous studies addressing similar topics have examined the implications of replication failure or prevalence of QRPs on the public's trust towards scientific research

\footnotetext{
${ }^{1}$ While outside of the scope of the current article, some arguments against the current open science movement have been expressed, ranging from the lack of diversity, how criticisms towards prior research are expressed and communicated ("tone debate"), and to a call for a more nuanced take in advancing science reforms. See Fox et al. (2021) and Freiling et al. (2021) for detailed discussions on these issues.
} 
(e.g., Anvari \& Lakens, 2019; Mede et al., 2020) rather than the effect of adopting open science practices directly. Few studies have examined whether the current open science movement can directly increase public trust toward scientific research (e.g., Rosman et al., 2020; Wingen et al., 2020), and even less work has examined this question in communication science. In addition, there is surprisingly scant empirical evidence of how open science practices are valued and appraised by fellow scientists (for rare exceptions, see Field et al., 2020, and Soderberg et al., 2021). While scientists rarely disagree with the normative principle of transparency and openness in research, they may nevertheless hesitate to adopt the current trends in open science in their daily research activities for various reasons. In sum, we ask: To what degree are current open science practices valued and appraised positively by the public and by academics? Can open science practices increase trust in science? We test these possibilities by relying on three preregistered experiments, sampling the general public as well as academics within the field of communication science.

\section{How Does the Public Evaluate (Open) Science Research?}

When evaluating scientific research, prior studies indicate the public bases their judgements of whom and what to trust based on authorities' expertise, their work ethic (i.e., integrity), and whether their self-interests conflict with that of the public (i.e., benevolence: Cummings, 2014; Hendriks et al, 2015; Resnik, 2011). Against this background, we expect research applying open science practices will be positively evaluated by the general public compared to research that does not apply open science practices. We reason that such evaluations may be based on two primary reasons.

First, the adoption of open science practices may operate as a heuristic cue signaling the overall "quality" of the research, and by extension, expertise of associated researchers. Although open science does not guarantee "good science" (see Markowitz et al., 2021), the public nevertheless may perceive a scientific study adopting open science practices to have 
taken extra time, effort, and contain additional rigor for quality controls — therefore evaluating such work to be of a higher quality than their counterparts. Scientists and their research are frequently trusted by the public as a reliable source of fair and accurate information (Hendriks, Kienhues, \& Bromme, 2020; Pew Research Center, 2019), and in this light, the public's improved perception of research quality for open science (versus non-open science) may mainly stem from the perceived expertise of the researcher (see Hendriks, Kienhues, \& Bromme, 2016, 2020), but not necessarily from the perception of integrity and the lack of self-interest presupposed by the logic of open science.

Second, open science practices - especially preregistration, open materials, and open data - may increase the perception of transparency and integrity in the scientific process and outcomes (e.g., Soderberg et al., 2021). Adopting open science therefore may decrease the perceived likelihood of research misdemeanors (i.e., increasing scientific integrity) and conflicts of interest (i.e., benevolence: "they act in best interests of the people, not of themselves"). A recent survey indicates that most Americans believe scientists are not transparent about potential conflicts of interest and their misdemeanors (Pew Research Center, 2019). More importantly, respondents indicate that they would put more trust in research findings when study data were openly available, or if findings were reviewed by an independent committee. Considering these public perceptions, if the general public perceives open science practices to be helpful in restricting researchers' degrees of freedom and thereby reducing malpractice as prescribed by the logic of open science, then they should evaluate research consistent with open science practices and their researchers as more credible and trustworthy. In this case, the public's increased trust towards research would stem from the perceived integrity and the lack of self-interest of the researcher and their research, and possibly in conjunction with the increased perception of expertise as well.

Prior studies concerning public trust towards scientific research generally find that 
privately-funded research is evaluated negatively (e.g., less scientific rigor and trustworthiness) compared to publicly-funded research due to potential self-interest motivations of private funding (Critchley, 2008; Krause et al., 2019). Since adopting open science practices in scientific research — and mentioning such practices when communicating with the public - is expected to increase the perceived transparency (Soderberg et al., 2021), this provides an ideal setting to test our predictions. That is, if the causal impact of open science on public trust and credibility towards science is indeed motivated by the perceived integrity and the lack of self-interests, mentioning open science practices should increase the public's trust and credibility equally to the degree that is expected for a publicly-funded research context, which is often perceived to be credible and trustworthy. Further, we may also expect that open science practices should compensate for the effect of the research context (publicly- vs. privately-funded research), such that privately-funded research employing open science practices will be evaluated just as positively as publicly-funded research without open science practices. Formally, we predict:

H1 (Studies 1-2): Research employing open science will be more positively evaluated by the general public on epistemic trust than research not employing open science

H2 (Study 2, only): Publicly-funded research will be more positively evaluated by the general public on epistemic trust than privately-funded research

RQ1 (Study 2, only): How is privately-funded research employing open science practices evaluated compared to publicly-funded research without open science practices?

\section{How Do Academics Evaluate (Open) Science Research?}

Recent discussions surrounding open science often focus on the issue of increasing the adoption of such practice in daily research activities (Dienlin et al., 2021; Nosek et al., 2015; Open Science Collaboration, 2015). Yet, for academics to readily adopt and internalize open science despite nontrivial barriers to do so, individual scholars must perceive intrinsic 
and extrinsic benefits for adopting such practices (Markowitz et al., 2021). Among many, one of the extrinsic benefits could be a more positive evaluation by fellow academics when research is consistent with open science practices. More positive evaluations of research by fellow academics provide a competitive advantage for scholars (e.g., journal publishing, tenure and promotion, etc.), which enhances one's professional standing (Clemens et al., 1995; Merton, 1968). Therefore, whether and how open science practices are valued by fellow scientists has implications for the adoption of open science among academics, and ultimately, for increasing the visibility of their work to broader audiences beyond academia. Within a scientific community, a primary means of scholarly communication and evaluation of scientific work is through journal publishing. While there are many ways that published scholarly work can signal scientific merit, a frequent heuristic for academics to evaluate scholarship is the journal that the paper was published in. Although it could be misleading to directly equate the impact metrics of a journal with the objective scholarly qualities of scientific works of which appear in that journal (Abramo et al., 2010), evidence indicates that quantitative impact metrics of a journal (such as journal impact factors or hindices) are systematically correlated with the subjective perception of prestige (Catling et al., 2009), thereby ultimately "signaling" the subjective quality of publication (Teevan, 1980).

Independent of journal outlets, recent research on this topic has begun to assess whether scientists more positively evaluate scholarship with open science practices than papers without open science practices - especially focusing on preregistration and registered reports - after presumed publication (Field et al., 2020) or during the peer-review process (Soderberg et al., 2021). As outlined in these works, preregistration and registered reports are designed to address researcher bias and to increase the credibility of the research process. Adopting them is therefore expected to increase the perception of transparency and trust towards scientific research and researchers following such practices. While the true impact of 
preregistration and registered reports on actual scientists' trust towards research with these practices are inconclusive so far (see, Field et al., 2020, for null effects, whereas see Soderberg et al., 2021, for positive findings), a survey of members of the German psychological society by Abele-Brehm et al. (2019) found that scientists' own attitudes towards open science practices were rather positive in general, although some had negative views about the consequences of data sharing and added requirements for conducting open science-consistent research. Recently, Bakker et al. (2021) reported that scholars in communication science perceive open science practices such as preregistration to improve the quality of the scholarship in the field. We therefore expect that, while studies published in high-impact journals will be evaluated more favorably than studies published in low-impact journals, studies with open science practices will be perceived favorably in terms of credibility and trustworthiness than studies without open science practices. Therefore, the following hypotheses are evaluated in Study 3:

H3: Research employing open science practices will be more positively evaluated by academics on scientific rigor (i.e., credibility) and trustworthiness compared to research not employing open science practices (i.e., main effect of open science)

H4: Research published in high impact journals will be more positively evaluated by academics on scientific rigor and trustworthiness compared to research published in low impact journals (i.e., main effect of journal prestige)

Moreover, consistent with the logic above, we expect employing open science practices will compensate for the effect of journal prestige but are unclear about the degree to which this compensation will occur. Accordingly, the following research question is posed:

RQ2: How are research articles published in low impact journals with open science practices evaluated compared to research articles published in high impact journals without open science practices? 


\section{Overview of the Current Paper}

We draw on the prior rationales to experimentally test how research with open science practices is perceived compared to research without open science practices. Our work extends prior research by examining how perceptions of scientists and their work change because of open science adoption or not (Study 1), in conjunction with the research context (e.g., publicly-funded vs. privately-funded work; Study 2) and as a function of different publication outlets (e.g., high-prestige vs. low-prestige journals; Study 3). Across three preregistered experiments (total $N=2,214$ ), our results using members of the general public and academics provide an understudied overview of how different stakeholders in the open science movement might change their perceptions based on such moderating factors.

\section{Study 1: Method}

In Study 1, we evaluate whether laypeople perceive research with open science to be more trustworthy, intelligent, and credible than research without open science. Study 1 received ethics approval from the second author's Institutional Review Board and was preregistered on the Open Science Framework (OSF), https://osf.io/58jyf/. The data collection occurred between September 14 and September 15, 2020 via online crowdsourcing platform CloudResearch, where we recruited approximately 1,500 participants (see pp. 13 of the Online Appendix for detailed information about sample size justifications, and pp. 4 to 11 for the results of the two pilot studies, stimuli, and protocols).

\section{Procedure and Measures}

Participants provided informed consent and saw the same opening instructions as the second pilot study (see the Online Appendix). We then introduced participants to open science, preregistration, and replication with definitions of the concepts and tested their comprehension. We stated, "It is possible that the summary you read will not contain any mentions of open science practices," and then participants were randomly assigned to read 
one of two stimuli from the second pilot study: (1) all open science categories, or (2) control. The same attention ("Did the article mention publicly available data, preregistration, or replication?") and comprehension checks ("What was the summary about?") were solicited in this study. We only used data from participants $(N=1,017)$ who answered the prior attention and comprehension questions correctly (excluded $n=489$ participants).

After reading their randomly assigned abstract that either contained open science practices or not, participants answered seven self-report questions about the credibility, intelligence, trustworthiness, and novelty of the author and their work (e.g., "How credible is this research?"). Descriptive statistics for these questions are located in Supplementary Tables S1 and S2. We ended the survey with demographic questions (e.g., age, gender, ethnicity, political ideology, and education level) and asked how often participants read science papers or science in the news on a scale of (1) Never to (5) Extremely often.

\section{Study 1: Results and Discussion}

After exclusions based on attention checks, we retained 1,017 participants (including those who did not respond to some demographic items, $N=11)$. After exclusion, we found no significant differences across conditions in terms of demographic characteristics except ideology (see pp. 14 of the Online Appendix for details). We therefore considered the effect of ideology on the results as a control variable, yet the results and conclusions remained consistent. For simplicity, we report results without ideology in the main text.

\section{Preregistered Main Results}

Table 1 reveals researchers and their work were appraised more positively if their abstract contained references to open science. Scientists and their work were consistently perceived as more credible $\left(d_{\text {scientist }}=.34 ; d_{\text {science }}=.46\right)$, intelligent $\left(d_{\text {scientist }}=.25 ; d_{\text {science }}=\right.$ $.26)$, and trustworthy $\left(d_{\text {scientist }}=.36 ; d_{\text {science }}=.39\right)$, but not more novel $\left(d_{\text {scientist }}=.09\right)$ if open science was mentioned in the abstract compared to when open science was not mentioned. 
Therefore, $\mathrm{H}_{1}$ is partially supported. Mentions of open science in research abstracts changed how scientists and their work were perceived by the public.

Table 1.

Study 1 Main Results, Among Those Who Correctly Identified OS Practices $(N=1,017)$

\begin{tabular}{cccccccccc}
\hline & \multicolumn{1}{c}{ OS } & Control & & & & \\
& $(n=626)$ & $(n=391)$ & & & & \\
& & & & & & \\
\hline Dependent Variable & $M$ & $S D$ & $M$ & $S D$ & $t$ & $p$ & Cohen's $d$ & $95 \% \mathrm{CI}_{d}$ \\
\hline Credibility & & & & & & & & \\
Scientist & 4.64 & 1.10 & 4.29 & 1.00 & 5.23 & $<.001$ & 0.34 & {$[0.21,0.47]$} \\
Science & 4.68 & 1.12 & 4.19 & 1.03 & 7.11 & $<.001$ & 0.46 & {$[0.33,0.58]$}
\end{tabular}

Intelligence

$\begin{array}{lllllllll}\text { Scientist } & 4.71 & 1.03 & 4.47 & 0.88 & 3.85 & <.001 & 0.25 & {[0.12,0.37]} \\ \text { Science } & 4.56 & 1.08 & 4.29 & 0.96 & 4.11 & <.001 & 0.26 & {[0.13,0.39]}\end{array}$

Trust

$\begin{array}{lllllllll}\text { Scientist } & 5.04 & 1.02 & 4.67 & 1.08 & 5.52 & <.001 & 0.36 & {[0.23,0.49]} \\ \text { Science } & 5.27 & 1.03 & 4.85 & 1.07 & 6.13 & <.001 & 0.39 & {[0.26,0.53]}\end{array}$

Novelty

$\begin{array}{lllllllll}\text { Scientist } & 4.37 & 1.25 & 4.48 & 1.11 & -1.45 & .147 & -0.09 & {[-0.22,0.03]}\end{array}$

Note. For the exact wording of each question, please see the Online Appendix. All self-report measures were 7-point Likert-type scales. 95\% $\mathrm{CI}_{d}=95 \%$ Confidence Intervals for Cohen's $d$ using 10,000 percentile-based bootstrap replicates. The control condition is the non-open science condition. OS = Open Science condition.

\section{Exploratory Analyses \& Robustness Checks}

As the exclusions were based on a post-treatment variable such as a manipulation check ( $N=360$ for control, and $N=131$ for open science condition), this may bias the 
estimates of true treatment effect (Aronow et al., 2019; Montgomery et al., 2018). We subsequently estimated intention-to-treat effect (ITE) while ignoring compliance status (i.e., correctly recognizing open science practice) in order to address this concern. Results indicate that those who were assigned to the open science condition, regardless of correctly recognizing open science or not, consistently rated scientists $(d=.15,95 \%$ bootstrapped CIs $=[0.05,0.26]$, using 10,000 percentile-based bootstrap replicates $)$ and their work $(d=.27$, $95 \% \mathrm{CIs}=[0.17,0.37])$ to be more credible than those in the non-open science condition. Such individuals also trusted scientists $(d=.21,95 \% \mathrm{CIs}=[0.12,0.32])$ and their work $(d=$ $.24,95 \%$ CIs $=[0.14,0.34])$ more. There were no significant differences in terms of perceived intelligence of scientists and their work, nor the novelty of their findings. We also observed a similar pattern when we estimated the complier-average causal effect (see Table $\mathrm{S} 3$ in the Online Appendix, and also see Table S4 for additional robustness check). These data suggest open science practices increased the perceived trustworthiness and credibility of a scientist's work but not the perceived intellectual merits.

The results of Study 1 offer initial causal evidence that scientists and their science were perceived as more credible, intelligent, and trustworthy by the general public when abstracts contained references to open science practices versus when they did not. However, the exact nature of this causal effect is still unclear. It is possible that the increased perception of research quality (as measured by credibility, intelligence, and trustworthiness) is indeed motivated by other factors, not necessarily from the promised benefits of open science practices such as an increase in perceived transparency and integrity of the researcher and their research (i.e., a lack of misdemeanors and researchers' self-interest). In Study 2, we address this point, illuminating the nature of this effect.

\section{Study 2: Method}

Study 2 was preregistered on the OSF (https://osf.io/5du3c), and data collection 
occurred between July 27 and July 31, 2021 via CloudResearch recruiting a total of 1204 participants (see pp. 20 of the Online Appendix for sample size justifications).

\section{Procedure and Measures}

After obtaining informed consent, we relied on identical protocols as to Study 1. We then orthogonally manipulated two factors - publicly- vs. privately-funded research context and adopting open science practice or not — in the description of the scientific research and researchers, creating a $2 \times 2$ between-subjects experiment.

Similar to the approach by Rosman (2020) and Chritchly (2008), participants were first presented with general information describing the work of scientists, who ostensibly conducted research about fear and humor appeals in a public health campaign. Participants in the open science condition $(N=591)$ were told that the researchers preregistered their hypotheses and made all relevant materials available for full transparency and public reuse. Comparatively, in the non-open science condition $(N=613)$, participants were told that the researchers did not preregister their hypotheses, nor did they make all relevant materials available for full transparency and public reuse.

For the research context factor, participants in the publicly-funded research condition $(N=596)$ were told that the research was being conducted at a large research-oriented public university, and researchers received grants provided by the federal government, while receiving the same salary and benefits compared to other academics at a given university. In the privately-funded research condition $(N=608)$, participants were told the scientists conducting the research were hired and funded by privately-owned social media companies, where they owned shares in the company and received salary and other benefits. Therefore, such scholars personally benefited from the results of their research.

Unlike the stimulus materials in Studies 1 or 3, the prior stimulus materials closely mirrored typical presentation formats from news outlets, science magazines, and online 
discussion forums. This decision was purposeful because members of the general public are more likely to be familiar with research summaries in this format (Pew Research Center, 2017), thereby aiming to achieve greater ecological validity. While the explicit mention of a lack of open science practices is rather rare in academic publications, it is common to find such mentions when research findings are communicated via popular press, science blogs, and/or social media discussions (e.g., see Elsesser, 2020, Oct). See Table A3 of the Online Appendix for the full descriptions of materials used in Study 2.

After reading the randomly assigned abstract, participants answered a modified version of the Muenster Epistemic Trustworthiness Inventory (METI: Hendriks et al., 2015). On a 7-point scale, thirteen semantic differential items assessed perceived expertise (e.g., “competent/incompetent," Cronbach's $\alpha=0.95$ ), integrity (e.g., "honest/dishonest," $\alpha=$ 0.93), and benevolence (e.g., "moral/immoral," $\alpha=0.95$ ) of the researchers described in the abstract they were exposed to. This inventory taps into different dimensions of the public's trust towards scientists and their work (Hendriks et al., 2015; König \& Jucks, 2019). Descriptive statistics for these questions are located in Supplementary Tables S5 and S6.

Participants were later presented with three manipulation check questions, one item about the research context and the other two about whether open science practices were presented or not in the abstract they exposed to. Consistent with our preregistration and Study 1, we excluded those who incorrectly answered any of the three manipulation check questions from the remaining analysis $(n=429$, therefore final $N=775)$, yet we also report the version of the analysis including those who did not pass them.

\section{Study 2: Results and Discussion}

After exclusion based on attention check question (see pp. 20 of the Online Appendix for details), we retained 775 participants; we find no significant differences across conditions in terms of age, ethnicity, or ideology, yet education was found to be significantly different 
across conditions $\left[\chi^{2}(18)=31.69, p=.023, \varphi=.117\right]$. Considering the impact of ideology (on passing manipulation check questions) and education (after exclusion), we additionally considered those as control variables, yet the results remain unchanged (see Table S7 in the Online Appendix). For simplicity, we only report results without covariates here.

Table 2. Study 2 Results, Among Who Correctly Identified Comprehension Check $(N=775)$

\begin{tabular}{lcccc}
\hline \multicolumn{1}{c}{ Effects } & $\boldsymbol{F}\left(\boldsymbol{d} \boldsymbol{f}_{1}, \boldsymbol{d} \boldsymbol{f}_{2}\right)$ & $\boldsymbol{p}$ & ${\text { Partial } \boldsymbol{\eta}^{2}}^{2}$ & $\mathbf{9 5 \%} \mathrm{CI}_{p e s}$ \\
\hline DV: Trust - Expertise & & & & \\
Publicly (vs. Privately) funded & $F(1,771)=67.107$ & $<.001$ & .080 & {$[.048, .120]$} \\
Open (vs. Non-Open) Science & $F(1,771)=161.140$ & $<.001$ & .173 & {$[.129, .220]$} \\
Public * Open Science & $F(1,771)=.142$ & .707 & .0002 & {$[.000, .007]$} \\
DV: Trust - Integrity & & & & \\
Publicly (vs. Privately) funded & $F(1,771)=109.043$ & $<.001$ & .124 & {$[.084, .169]$} \\
Open (vs. Non-Open) Science & $F(1,771)=117.837$ & $<.001$ & .133 & {$[.090, .179]$} \\
Public * Open Science & $F(1,771)=.326$ & .568 & .0004 & {$[.000, .009]$} \\
DV: Trust - Benevolence & & & & \\
Publicly (vs. Privately) funded & $F(1,771)=168.426$ & $<.001$ & .180 & {$[.133, .228]$} \\
Open (vs. Non-Open) Science & $F(1,771)=155.119$ & $<.001$ & .170 & {$[.122, .215]$} \\
Public * Open Science & $F(1,771)=.916$ & .339 & .001 & {$[.000, .011]$} \\
\hline
\end{tabular}

Note: $95 \% \mathrm{CI}_{p e s}=95 \%$ Confidence Intervals for partial $\eta^{2}$ using nonparametric case bootstrapping $(N=10,000) .95 \% \mathrm{CI}_{p e s}=95 \%$ Confidence Intervals for partial $\eta^{2}$ using 10,000 percentile-based bootstrap replicates.

\section{Preregistered Main Results}

Table 2 contains a summary of the results, where we find strong support for $\mathrm{H}_{1}$ and $\mathrm{H}_{2}$. Participants perceived scientists who conducted research adhering to open science practices to have more expertise (partial $\eta^{2}=.173,95 \%$ bootstrapped 95\% CIs $[.129, .220]$ ), more integrity (partial $\eta^{2}=.133,95 \%$ CIs $[.090, .179]$ ), and to be more benevolent (partial $\eta^{2}$ 
$=.170,95 \%$ CIs $[.122, .215])$ than those not adhering to open science practices, supporting $\mathrm{H}_{1}$. Likewise, participants perceived scientists who conducted research in a public setting to have more expertise (partial $\eta^{2}=.080,95 \%$ CIs $[.048, .120]$ ), more integrity (partial $\eta^{2}=$ $.124,95 \%$ CIs $[.084, .169]$ ), and to be more benevolent (partial $\eta^{2}=.180,95 \%$ CIs [.133, .228]) than those conducting research in a private setting, supporting $\mathrm{H}_{2}$. However, we did not find a significant interaction effect between the research context factor and the open science factor in predicting epistemic trust towards scientists. This result suggests the effect of the open science factor is not dependent upon the research context factor.

\section{Exploratory Analyses \& Robustness Checks}

Regarding RQ1, we probed the pairwise comparisons between experimental conditions (see Figure S1 in the Online Appendix for full details). A series of post hoc comparisons using nonparametric bootstrapping of differences in means suggested that perceived researcher integrity for research within a public setting without open science is indistinguishable from that of research within a private setting with open science, diff $=$ $.0252,95 \%$ bootstrapped CIs $=[-.1604, .2067]$. Likewise, we found no significant difference in terms of public's perception of benevolence, diff $=-.0508,95 \%$ CIs $=[-.3553, .2455]$. However, we found that research within a private setting with open science is evaluated as having more expertise than research within a public setting without open science practice, diff $=.4129,95 \% \mathrm{CIs}=[.1303, .6842]$. This demonstrates employing open science may improve the public's perception of trust regarding scientists by increasing perceived transparency and lowering the perception of misdemeanors and researchers' own self-interest. These results are consistent with the purported benefits prescribed by the logic of open science, where adopting open science may increase the perception of integrity and the lack of self-interest - thereby restoring public trust towards science.

We also performed additional exploratory analyses and robustness checks against our 
methodological and analytic decisions by estimating ITE and additional linear models with covariates. The results did not change regardless of the inclusion versus exclusion of those who did not pass the comprehension checks or if the linear models contained additional covariates (these results are fully reported in the Online Appendix, Table S8 to S9).

Taken together, Study 2 shows that employing open science practices increased the public's trust towards scientists by increasing the perceived integrity (e.g., lowering the perception of misdemeanors and self-interest) and perceived benevolence of their work. However, it is still unclear whether increased public trust and positive evaluations of scientific research were driven by a priming effect or by demand characteristics of the experimental setup, since we explicitly provided definitions of open science practices before participants were exposed to article abstracts (Study 1) or the description of research studies (Study 2). The former concern is especially warranted given that the general public is rarely exposed to discussions related to open science practices and their implications. Study 3 explicitly aims to mitigate such concerns by directly exposing participants (e.g., actual communication researchers) to abstracts of studies without prompting beforehand what open science practices are and how they are performed. In addition, investigating the implications of open science practices in the evaluation of scientific work by communication researchers may provide insights into how scholars think and feel about the issues.

Compared to the general public, academics are relatively well-aware of the philosophy and principles of scientific research. Given the current prominence of the open science discourse among academic communities, academics will likely have heard about and self-appraised the value of open science for their own field. Therefore, using an academic sample, we test whether greater awareness towards open science practices increases positive evaluations of scientific research adhering to such practices. In conjunction with the journal prestige factor, which is the most frequent heuristic for academics to evaluate the quality of 
scholarship, adopting open science may have a net positive impact on evaluations of scientific research by fellow academics if academics indeed value open science practices in their field. By testing this prediction, Study 3 is expected to provide rare empirical evidence assessing whether research consistent with open science practices is indeed positively evaluated by fellow academics. This logic is often assumed, but not empirically evaluated within open science communities and related empirical research.

\section{Study 3: Method}

\section{Data Collection}

Study 3 was preregistered on the OSF (https://osf.io/675r4/), and data collection occurred between September 8 and September 25, 2021. Our target population was communication scholars who actively publish research articles in major communication journals, defined as all first or corresponding authors who have published in several major communication journals (see Chan \& Grill, 2020; Song et al., 2020). We targeted authors whose contact details were listed in the ISI Web of Science article record for research articles published in target journals/articles from January 2002 to April 2019. See the online supplementary materials for detailed information about identified journals and articles.

We chose communication science as the context of the study for two reasons. First, communication is often characterized as a "multidisciplinary field," where the structure and scholarly discourses in the field are vastly heterogeneous (Song et al., 2020; Waisbord, 2019). Second, the introduction and adoption of open science practices are still relatively new within the communication field (Dienlin et al., 2021). Therefore, within communication science, there exists more heterogeneity in familiarity and engagement with open science practices (see Bakker et al., 2021; Markowitz et al., 2021). This allowed us to experimentally test our expectations regarding the causal impact of open science on trust towards scientific research in an ecologically valid way, among a population where open science is not fully 
ingrained into the fabric of the field.

To obtain the contact details (i.e., email address) of the authors, we programmatically scraped all metadata of research articles published in the target journals following similar approaches by Song et al. (2021). We retained all authors except those who were authors of reviews or editorials. Through this procedure, we identified a total of 13,312 authors and all identified researchers were contacted upon removing duplicates (final $N=11,859$ : see pp. 30 of the Online Appendix for the sample size justification based on a priori power analysis). Every eligible respondent received at least one additional reminder if they did not respond to the initial invitation. There was no compensation for participating in this experiment.

Among 11,859 who initially invited to participate to the study, we received 912 responses (including any item missing and partial responses). ${ }^{2}$ Excluding 12 explicit refusals (i.e., they did not consent to participation) and 1 additional dropout immediately after the consent, our final eligible sample size was 899 (AAPOR Response Rate 1 \& 2: 7.7\%).

\section{Procedures and Stimulus Materials}

Upon obtaining informed consent, participants were asked about their research orientations (e.g., whether they identify mainly with quantitative approaches, qualitative approaches, or a mixture of both) and overall familiarity with the recent "replication crisis" in social science. Then, participants were presented with four hypothetical journal abstracts, all of which showed recently published articles with their titles, author names, and abstract text as they appear in typical online research articles. We adapted and modified abstracts from the target journals as stimuli (e.g., Coronel et al., 2021; Merrill \& Afifi, 2017; Oliver \& Raney, 2011; Skurka et al., 2018; Wirth et al., 2012) to create ecologically valid stimuli.

\footnotetext{
${ }^{2}$ In our email invitation to potential respondents, we made no explicit reference to open science practices but mentions "research practices" in a very generic way (see pp. 46 of the Online Appendix for detailed wordings). Therefore, the possibility of open-science-interested respondents participating our survey would be unlikely because the aim of the research is unknown from this recruitment email.
} 
Research Outlet. We randomly assigned participants to one of the two research outlet conditions (high-impact journal vs. low-impact journal), which served as the betweensubjects factor in the experiment. For the "high-impact journal" condition, we created abstract page views of research articles purportedly from one of the four high-ranking flagship journals in the communication field (Journal of Communication [H-index $=131]$, Communication Research [104], Journal of Computer-Mediated Communication [119], and Human Communication Research [89], all with H-indices above 50). Stimuli in the "lowimpact journal" condition were four regional, non-flagship journals (Atlantic Journal of Communication [H-index =14], Western Journal of Communication [43], Asian Journal of Communication [27], and Southern Communication Journal [25], all with H-index below 50). We chose these eight journals since they all represent sufficiently general outlets in the field while they are all from renowned publishers (Oxford University Press, Sage, and Taylor \& Francis). ${ }^{3}$ We fully randomized the journal outlet across all four trials (see below), and research outlets were later collapsed into high vs. low impact journal conditions as there were no significant differences across specific journals in evaluations of trust and research quality except for trust towards findings. Controlling the specific journal names in the analysis did not change the main conclusion and findings (see Online Appendix for details). For simplicity, we only report results without covariates here.

Open Science. We also manipulated the open science factor in our experiment, which was a within-subjects factor. We manipulated whether (purportedly) published articles displayed open science badges (Open science condition: see Figure A1 in the Online Appendix) or not (control condition) next to the article title in their abstract page views. These badges are widely used in many social science journals, including those in

\footnotetext{
${ }^{3}$ This also helps us to control any esthetic features of the journal articles (see below treatment materials) essentially very similar across conditions, increasing the internal validity while maximizing the ecological validity of our manipulation.
} 
communication science, for papers adhering to open science principles. Studies indicate displaying such badges are highly effective in promoting appropriate norms for open science (Kidwell et al., 2016) as well as increasing trust in scientists (Schneider et al., 2020). Across four repeated trials, we presented two randomly chosen research articles with open science badges and two without open science badges in a fully balanced and randomized order.

Research Topics. We randomly varied topics of the research articles across trials to properly isolate the impact of open science and that of journal prestige factors from the topic of the research (stimulus sampling: Wells \& Windschitl, 1999). The topic factor was fully balanced and randomized across four repeated trials, treated as the random effect in the analysis (see Online Appendix for details).

Together, across all factor combinations, this procedure created 64 unique treatment regimes, which collapsed into a $2 \times 2$ (high vs. low impact journals $\times$ open science or not) mixed design with 2 repeated trials within each treatment regime (see Table 3). Figures A2 and A3 in the Online Appendix show exemplary materials for this treatment.

Table 3. Treatment Conditions, Study 3

\section{Within-factor}

Between-factor

High impact journals

Low impact journals
Open Science Badges

Condition 1

Condition 3
No Open Science Badges

Condition 2

Condition 4

Note: In each condition, there are 16 possible treatment arms (journal and topic combinations). Participants were first randomly assigned to one of the high- vs. low impact journal conditions, and then presented with a total of four stimuli in a randomized order (i.e., two abstracts from the Open Science Badges condition, and two abstracts from the No Open Science Badges condition).

\section{Measures}

For each of the four trials, we asked participants to evaluate quality of the researchers 
and their findings described in the abstract using the self-report questions similar to those in Study 1 (e.g., "How credible is this research?). Yet, instead of relying on a 5-point scale as in Study 1, we presented the question with a 101-point feeling thermometer (0-100, inclusive). Descriptive statistics for these questions are located in Supplementary Tables S11 and S12.

After the treatment, participants completed a block of questions related to their background information such as gender, year they received (or expect to receive) their Ph.D., degree of engagement with open science practices, seniority, and location in which they are professionally based. Finally, participants were debriefed.

\section{Key Sample Characteristics}

Most of our sample was quantitatively-oriented scholars $(N=422,46.94 \%)$, yet we obtained a good representation of qualitative scholars $(N=170,18.9 \%)$ or those who employ a mix of both approaches $(N=282,31.3 \%)$, reflecting the general research orientation of the field. Our sample was also heterogeneous in terms of the year in which academics were (or expected to be) conferred for their Ph.D. (Median $=2010, S D=12.10)$, and the sample included a diverse range of academic ranks from early-career researchers — such as MA/Ph.D students $(N=21,2.3 \%)$, postdocs $(N=41,4.5 \%)$, and assistant professors $(N=$ $119,13.2 \%)$ - to associate $(N=150,16.6 \%)$ and full professors $(N=173,19.2 \%)$. A small

portion of respondents indicated they work as lecturers or non-tenure track $(N=21,2.3 \%)$, or even no longer active in academia $(N=44,4.9 \%)$. Nearly $37.2 \%$ did not disclose their academic ranks $(N=334)$. The majority of participants said that they heard or read about the replication crisis $(N=695,77.3 \%)$, although there were a sizable proportion of scholars who were not aware of the issue $(N=188,20.9 \%)$.

During the experiment, we gauged participants' self-reported engagement with open science practices (measured on a 5-point scale from "not at all" $=1$ to "always" $=5: M=$ 2.70, $S D=1.10)$. A one-way ANOVA indicated research orientation was significantly 
associated with engagement with open science, $F(2,558)=26.21, p<.001$, such that quantitative researchers $(M=2.94, S D=1.09)$ and mixed approach researchers $(M=2.73$, $S D=1.04)$ were more likely to report that they engage with open science practices than qualitative researchers $(M=2.07, S D=0.99)$. Excluding lecturer/non-tenure track, those no longer in academia, and those who did not disclose their academic seniority, we also found that seniority was significantly associated with self-reported engagement with open science, $F(4,495)=2.817, p=0.025$, such that MA/PhD students $(M=3.18, S D=0.95)$ are most likely to report that they engage with open science practices, followed by Postdoctoral researchers $(M=3.05, S D=1.07)$, Assistant $(M=2.77, S D=1.08)$ and Full Professors $(M=$ 2.73, $S D=1.10)$. Associate professors $(M=2.54, S D=1.02)$ were least likely to report their engagement with open science practices. While the differences in engagement with open science were rather mild, our sample characteristics nevertheless suggest the degree of engagement with open science is likely to vary across our sample of respondents, providing an important setting to test our hypotheses without unnecessarily prompting respondents about open science (thus, overcoming the limitations of previous Study 1 and Study 2). Additional sample characteristics are reported in the Online Appendix, p. 30.

\section{Study 3: Results and Discussion}

We found no significant differences across our between-subjects conditions (i.e., journal prestige factor) in terms of researchers' research orientations $\left[\chi^{2}(2)=3.083, p=.214\right.$, $\varphi=.059]$ nor whether they were aware of the replication crisis $\left[\chi^{2}(1)=1.445, p=.229, \varphi=\right.$ .04]. Within each journal prestige factor, we found no significant differences across specific journals in terms of evaluations of researchers and their research (all $p \mathrm{~s}>.074$, see Table S10 in the Online Appendix for details) other than trust towards research. Inclusion of the specific journal outlet factor, however, did not change the results.

\section{Preregistered Main Results}


Figure 1 reports the results addressing our hypotheses (see Online Appendix Tables S14 and S15 for full details). Participants perceived articles with open science badges to be more credible $(b=1.329, S E=0.528, p=0.012)$ and the authors as more credible $(b=1.394$, $S E=0.468, p=0.003$ ) compared to articles without open science badges. Furthermore, the open science factor significantly increased trust evaluations towards research $(b=1.722, S E$ $=0.562, p=0.002)$; however, it did not influence the perceived trustworthiness of the scientist who wrote such an article $(b=0.569, S E=0.473, p=0.229)$. The open science factor did not increase the perceived novelty of scientists who wrote the article $(b=0.604, S E$ $=0.610, p=0.322$ ). While this result only partially confirms $\mathrm{H}_{3}$, it suggests there is no causal influence of open science on how scientists perceive fellow scientists, but scientists themselves positively evaluate the work of others when such work is consistent with open science practices. Consistent with the general logic outlined in this paper, open science practices increased the perceived credibility and trustworthiness of the research findings but not trustworthiness or novelty of the researchers.

Testing $\mathrm{H}_{4}$, participants rated journal articles published in high prestige outlets to be more credible $(b=3.649, S E=1.578, p=.021)$ than articles published in low prestige outlets. ${ }^{4}$ When articles appeared in a high prestige journal, participants perceived the author to be more credible $(b=4.065, S E=1.581, p=0.010)$. While participants rated that authors produce more novel ideas when their articles appeared in a high prestige journal, this effect was not significant $(b=2.851, S E=1.580, p=0.071)$. Therefore, $\mathrm{H}_{4}$ was partially supported.

\footnotetext{
${ }^{4}$ Due to the way that variance is partitioned in linear mixed models (Rights \& Sterba, 2019), there is no agreed-upon way to calculate standard effect sizes in mixed models. We opted to report unstandardized regression coefficients instead as both of the experimental factors were scaled on a 0-1 range, therefore directly comparable with each other. Besides, commonly reported standardized effect size measures may suffer from nontrivial problems such as ambiguity of selecting appropriate standard deviation units, reliability, and range restrictions (see Pek \& Flora, 2018, and Baugley, 2011, for detailed discussion on this issue), which advocates the use of unstandardized - a more robust and meaningful - effect size.
} 

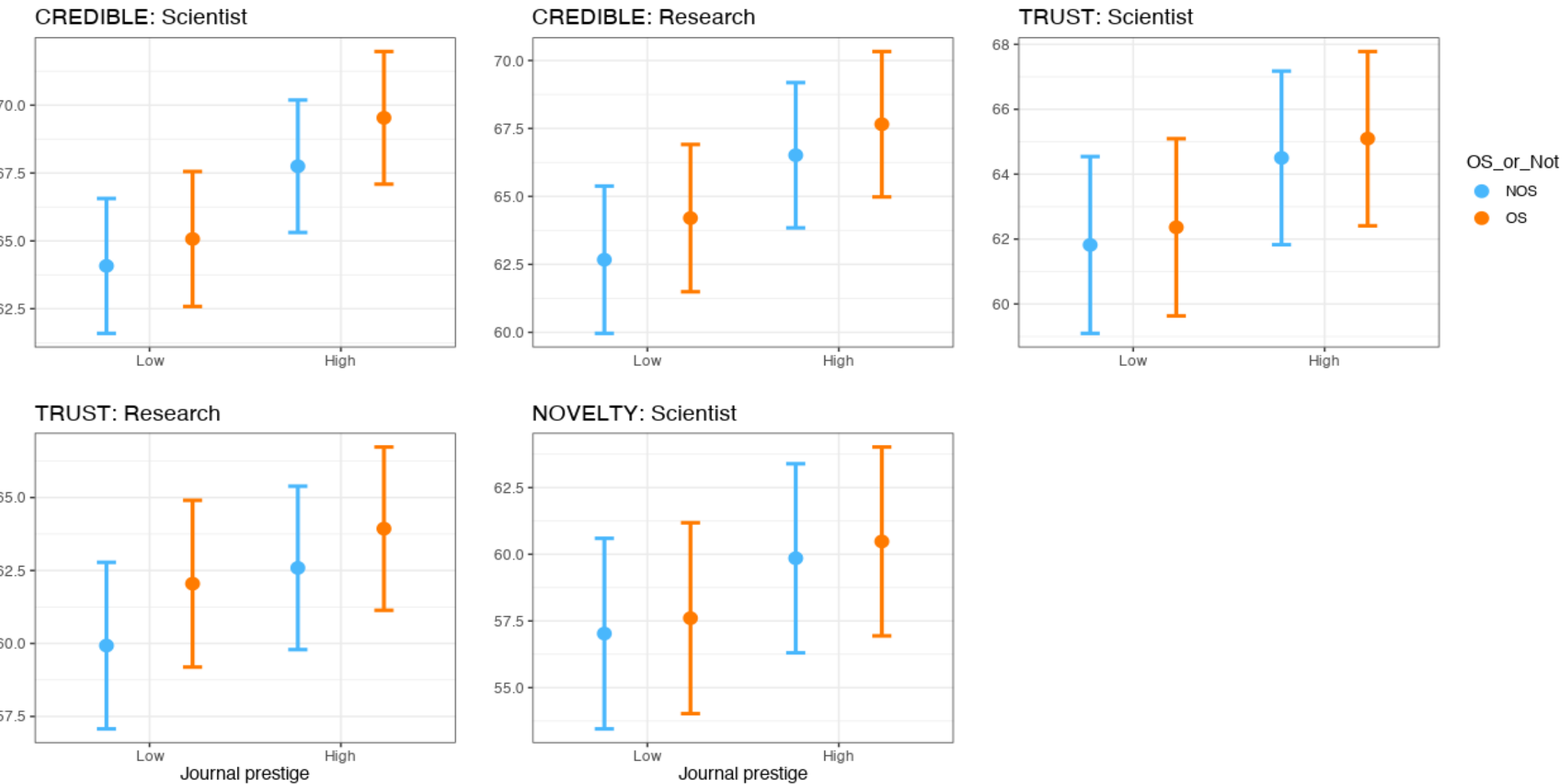

Figure 1. Causal effect of journal prestige and open science in evaluations of researcher and research quality, Study 3.

Note: The y-axis denotes each dependent variable score (as in each panel title). The x-axis denotes journal prestige factor (High vs. Low), and colors in each barplot indicate open science factor (OS: Open science, NOS: Non-open science). Each dot represents a point estimate, and vertical error bars represent $95 \%$ CIs. None of the interactions were statistically significant, suggesting that the effect of open science factor is independent of journal prestige factor. 


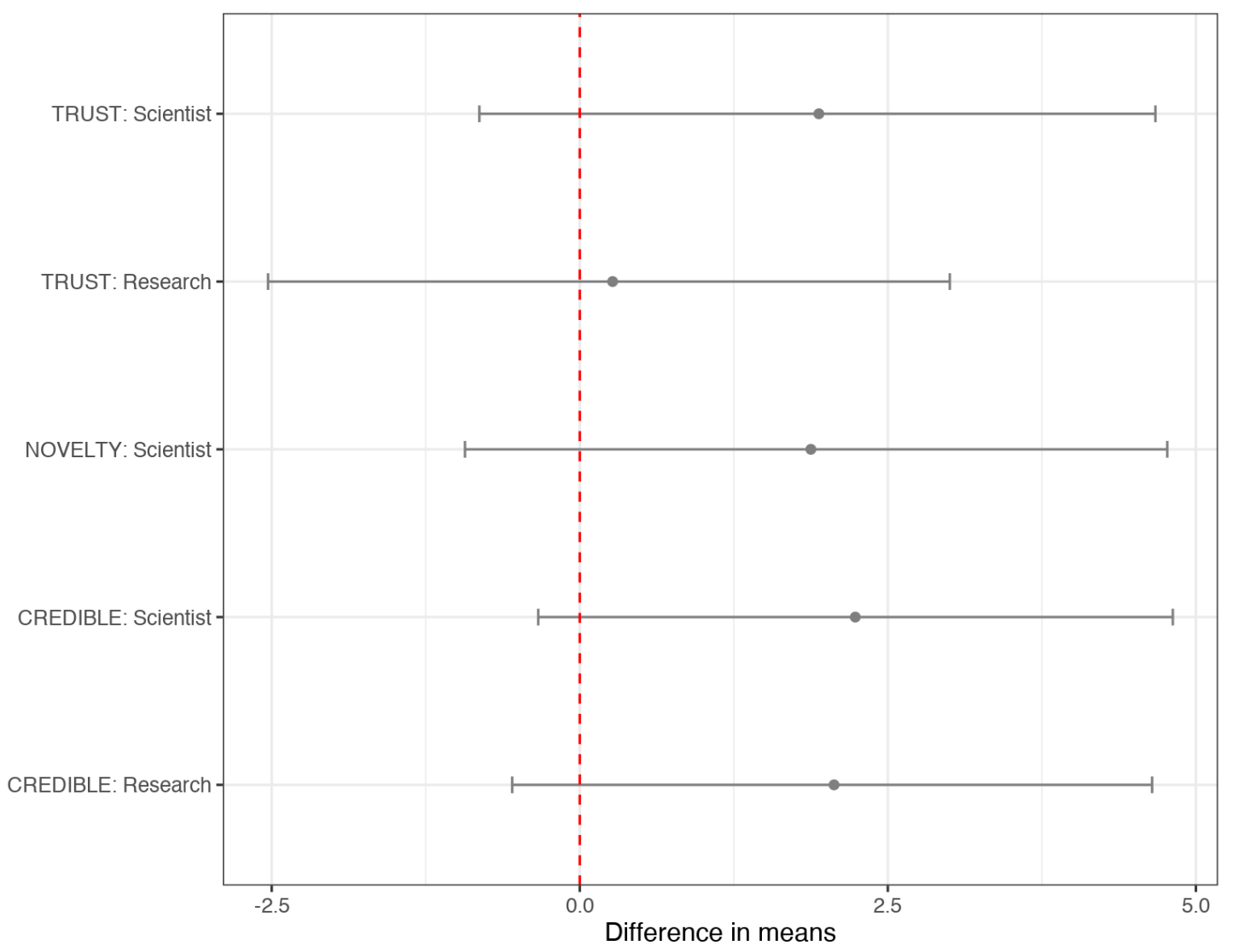

Figure 2. Differences in means, comparing non-open science with high prestige journals vs. open science with low prestige journals, Study 3.

Note: Each dot represents a point estimate of differences in means, and vertical error bars represent $95 \%$ Cis.

Across all model specifications, the causal impact of the open science factor was not contingent upon journal prestige (see Online Appendix Table S14 for details), indicating that the size of the effect of the open science factor is consistent across the journal prestige factor. Per our RQ2 and as displayed in Figure 2, we found no significant differences between estimated marginal means for evaluations of research articles (and their authors) published in low impact journals with open science practices compared to research articles published in high impact journals without open science practices (all bootstrapped CIs straddle zero).

\section{Exploratory Analyses and Robustness Checks}

Prescribed benefits of open science, as well as scholarly discussions surrounding the 
open science movement, suggest greater awareness towards open science practices may increase positive evaluations of research articles adhering to such standards. Our heterogeneous sample of communication scholars enabled us to directly test whether such expectations are consistent with evaluations by academics. Figure 3 presents the results of such tests, where we probe the possible heterogeneity of the impact of the open science factor across several key covariates (see Figure A6 in Online Appendix for additional results for gender, main disciplinary identification, and professional location of researchers).

First, self-identified quantitative scholars perceived scientific research with open science practices to be more credible $(b=2.424,95 \%$ bootstrapped CIs [1.043, 3.773], all CIs based on parametric bootstrapping with $N=10,000)$ and trustworthy $(b=2.399,95 \%$ CIs $[.892,3.918])$, compared to qualitative or mixed-method scholars. Those who indicated they were aware of the replication crisis also showed a similar pattern (credible: $b=1.796,95 \%$ CIs [.673, 2.903]; trustworthy: $b=2.421,95 \%$ CIs $[1.249,3.615])$ compared to those who reported they did not know or had not heard about the issue.

Lastly, we also probed whether academic seniority associated with the positive evaluation of research articles with open science practices. Excluding lecturer/non-tenure track, those who are no longer in academia, or did not disclose their academic seniority $(n=$ 399 removed), we found that seniority is inversely related to the positive evaluation of research with open science practices. While there was no positive impact of open science among associate and full professor ranks, early-career researchers such as MA/PhD students and postdocs were more likely to positively evaluate the credibility of research (among students: $b=10.834,95 \%$ bootstrapped CI $=[4.209,17.317]$; among postdocs: $b=4.990$, $95 \% \mathrm{CI}=[1.912,8.096])$ and associated researchers (among students: $b=6.643,95 \% \mathrm{CI}=$ $[0.198,12.955]$; among postdocs: $b=3.573,95 \% \mathrm{CI}=[0.991,6.175])$, as well as the trustworthiness of researchers (among student: $b=8.260,95 \% \mathrm{CI}=[2.221,14.182]$; among 
postdocs: $b=3.223,95 \% \mathrm{CI}=[0.435,5.884])$ and of their research (among student: $b=$ $7.358,95 \% \mathrm{CI}=[1.329,13.340]$; among postdocs: $b=5.484,95 \% \mathrm{CI}=[1.894,8.970])$ when articles featured open science practices (compared to when they did not). Those with an assistant professor rank showed the similar pattern (credibility for scientists: $b=2.080,95 \%$ $\mathrm{CI}=[0.209,3.941]$; credibility for research: $b=2.324,95 \% \mathrm{CI}=[0.288,4.321])$, yet their trustworthiness judgements of research and researchers were not affected by open science.

In addition to the results described above, we also asked communication scholars to evaluate the quality of research based on an APA-formatted abstract and title which contained cues for open science practices or not while stripping out the causal impact of journal prestige on article evaluation (see pp. 35 - 38 of the Online Appendix Tables A4 and A5, along with Figures A4 and A5, for details of this secondary treatment). Controlling for article topic, abstracts containing open science cues were more likely to be perceived as making positive contributions than abstracts not containing open science cues $(b=0.292, S E$ $=0.073, p=.0001,95 \% \mathrm{CIs}=[0.092,0.447]$ based on $N=10,000$ parametric bootstrapping) Our respondents also indicated they would be more likely to send out the manuscript for peer review if the abstract mentioned open science practices compared to no open science practices $(b=0.269, S E=0.090, p=.003,95 \%$ Bootstrapped CIs $=[0.145,0.441])$. Combined with the main results and robustness checks, these data demonstrate the causal impact of open science on perceptions of trust and credibility of research. 

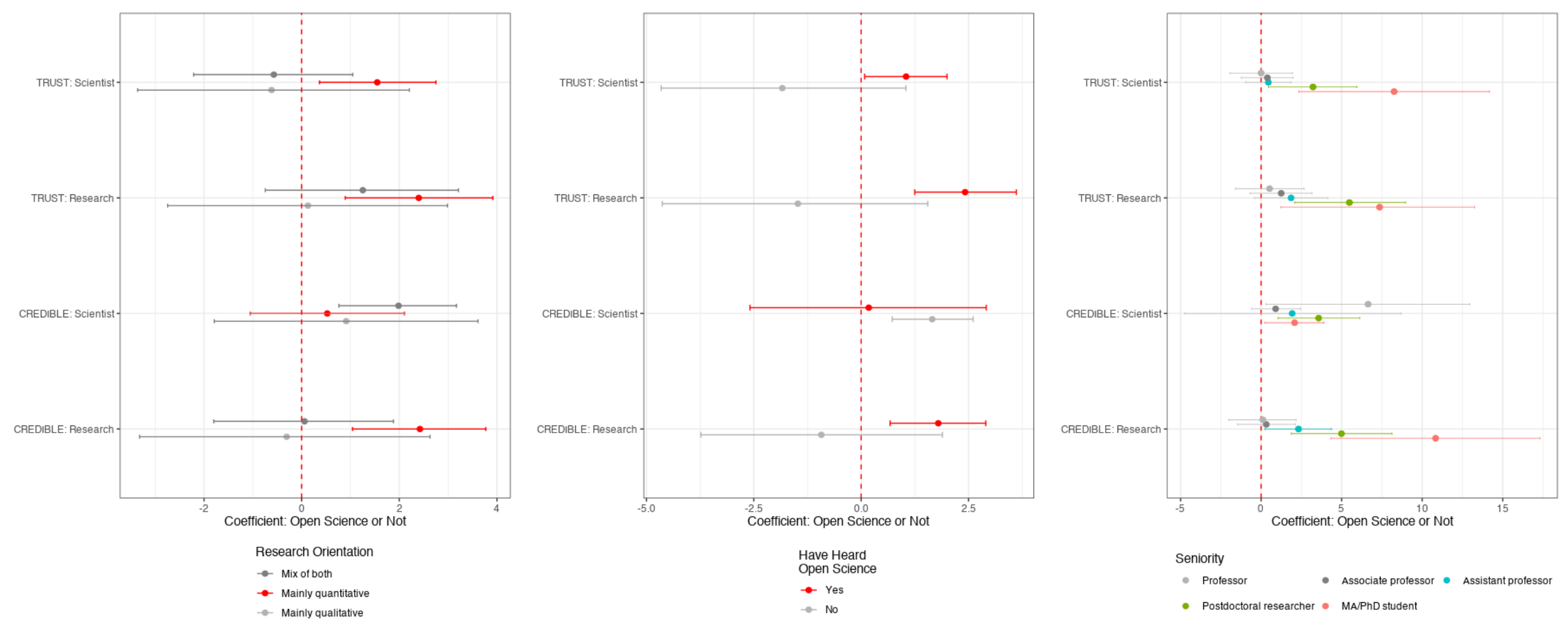

Figure 3. Effect heterogeneity as a function of pre-treatment covariate and academic seniority, Study 3.

Note: $\mathrm{x}$-axis denotes the regression coefficient for the open science factor, separately estimated conditional for each level of covariates as described in the legends of the panels in Figure 3. Each dot represents a point estimate, and vertical error bars represent 95\% CIs. Quantitative scholars, those who have heard about discussions related to open science, and early-career researchers (students and postdocs) are more likely to positively evaluate researchers and findings when such research employs open science. 


\section{General Discussion}

The current paper aimed to address the assumed, yet rarely substantiated, promises and benefits of open science practices — the argument that more transparent research standards adhering to open science may rescue eroding public trust in science (e.g., Besançon et al., 2020; Dienlin et al., 2021). Previous research addressing similar questions, so far, reported mixed results (e.g., Anvari \& Lakens, 2019; Hendriks et al., 2020; Wingen et al., 2020). While recent observational evidence suggests open science-consistent research especially, registered reports — is evaluated more positively during the peer review process than non-open-science-consistent research (Soderberg et al., 2021), there was a lack of comprehensive, causal evidence of whether open science practices could increase trust towards scientists and their work. Our empirical package addressed this shortcoming by conducting three preregistered experiments, observing that the public and academics perceive open science research to be more trustworthy and credible than non-open science research.

Although the public is generally less aware of the problems of QRPs and proposed solutions to mitigate such concerns, Study 1 and Study 2 demonstrated that, once introduced and familiarized, they can identify research with open science practices and also evaluate them more positively than research without open science practices. Study 1 also found that correctly recognizing open science practices increases the causal effect of open science on evaluations of research quality. Together, these results consistently suggest adopting open science practices in academic research has the potential to increase public trust toward scientific findings and associated researchers. In addition, Study 3 identified that academics, on average, also positively evaluated scientific findings when such research followed open science principles compared to not following open science principles. Those who were aware of the replication crisis, less senior (i.e., early-career) researchers, and more quantitativelyoriented scholars were mostly responsible for the observed effect, additionally corroborating 
the prediction that greater awareness and familiarity toward open science may increase the accurate recognition and more positive evaluations of such research. Across Study 2 and Study 3, we also observed that the causal impact of open science on trust evaluations are largely independent with, therefore robust against, possible confounds (such as the research funding or journal prestige). This demonstrates the potential for open science practices to increase general trust toward scientific findings, substantiating one of the prescribed benefits of open science practices described in recent commentaries and discussions (Dienlin et al., 2021; Markowitz et al., 2021; Nosek et al., 2015; Soderberg et al., 2021).

\section{Limitations and Future Directions}

As with all research, our study is not without limitations. In Study 1 and 2, we first introduced the definition of open science practices to participants and checked their comprehension of such practices, followed by exposing them to stimulus materials. This process may have introduced possible demand characteristics or experimental priming effects for our measures. However, as discussed by Mummolo and Peterson (2019), in typical online surveys featuring depersonalized interactions between researchers and subjects, online subjects often fail to correctly guess the true experimental intent of research - even when subjects are fully informed about an experimenter's hypotheses (note, participants were not told about any hypothesis for the studies reported here). Relatedly, by presenting definitions of open science practices, we avoided any strong normative assessment of such practices, and we did not indicate whether open science was inherently desirable or undesirable for "good science." Instead, we provided open science definitions in a relatively value-neutral way (see Tables A1 and A2 of the Online Appendix for details). While we cannot definitively rule out experimental priming or possible demand effects for Studies 1 and 2, additional tests did not find evidence that the mere exposure to open science articles was associated with affective rating differences compared to the mere exposure to non-open science articles (see p. 8 and p. 
10 of the Online Appendix for details for this additional test), suggesting that positive evaluations found in Studies 1 and 2 are unlikely to be the result of priming participants in a certain affective way about open science. Nevertheless, future research should detect and mitigate possible demand effects or affective priming when assessing the impact of adopting open science on public trust.

Second, our heterogeneous samples involving the general public and academics are large and diverse, yet their generalizability may be constrained, as those who participated in our experiment do not come from probability samples. While this does not invalidate our experimental setup nor our conclusions regarding the causal impact of open science on trust, our results cannot speak for population estimates of what the general public or researchers (especially outside of communication science) think about open science practices. Moreover, our experimental setups only involved a single, particular geographic and cultural context (i.e., U.S.), and communication science is nontrivially dominated by Western researchers (Chakravartty et al., 2018). The underrepresentation of non-WEIRD samples (Henrich, Heine, \& Norenzayan, 2010) may additionally limit the generalizability of our findings.

Lastly, throughout this article, we focused on a few dominant categories of open science including replication, open data and materials, and preregistration. While these categories are dominant in the current open science literature, "openness" entails a spectrum of other activities as well. Many additional aspects of open science—-such as open access publishing, open peer review, or "citizen science" — are not evaluated here. Although there are considerably more mixed reactions towards such aspects among academics (for instance, see Bahlai et al., 2019; Grand et al., 2012), relatively less is known how the general public or other stakeholders (e.g., journalists, funders, or policy makers) may evaluate such components. Evaluating the implications of other aspects of open science, and also for other interested parties, may reveal how scientific research and associated scientists are judged by 
various stakeholders.

\section{Implications for Open Science and Communication Research}

While the generalizability of our findings deserves more empirical scrutiny and additional inquiry, the findings in this paper have implications for our field and for various stakeholders. The fact that the general public positively valued open science practices in a manner consistent with the ideals of the open science movement suggests the general public also intrinsically agrees with the ideals of open science and shares a similar understanding of what makes "good science." Considering that scientific communities and the general public often sharply disagree on a wide range of issues and subject matters (e.g., the importance of vaccinations during a public health crisis), we believe this finding has nontrivial implications to enhance public trust towards scientific research.

However, on a broader level, our results also raise the alarm over risks of improper instrumentalization of open science practices without truly engaging in such practices. One concerning practice is "open washing" - poor research superficially implementing open science (e.g., researchers preregistering every possible hypothesis, readers failing to check factual claims but only using open science indicators such as the badges as heuristics for good research). Whereas such concerns are widely shared by both critics and advocates of open science in communication (see Dienlin et al., 2020; Fox et al., 2021), our results also imply that such practices have the potential to drive a false sense of trust and credibility. As summarized in Markowitz et al. (2021), "the absence of open science does not guarantee bad science, nor its mere presence guarantee good science" (p. 758). We therefore believe "studies employing open science practices need to be evaluated just as carefully as traditional studies" (Dienlin et al., 2020, p. 18), and there is a strong need for scholars, reviewers, and editors to ensure open science accurately and faithfully reflects the goals of the research.

Lastly, while the open science movement is lionized by its advocates to be novel and 
a communalistic solution to many problems of "closed" science, there certainly exist various individual or institutional barriers that make current open science practices more accessible and convenient to some scholars but not others - the lack of proper training in open science methods, upfront and increased cost of engaging open science versus uncertainty in its benefits, and inconsistent cultural norms across different communities are just a few notable barriers (Dienlin et al., 2020; Fox et al., 2021; Markowitz et al., 2021). Arguably, some of these barriers appear to be more pronounced among certain subgroups such as early career researchers, certain subfields of communication, and scholars from non-WEIRD nations (e.g., see Fox et al., 2021). Thus, the current open science movement in communication may systematically disadvantage those groups, and by extension — considering our results may further limit the perceived credibility and trustworthiness of their findings. Although the open science movement can help to remedy many empirical problems, there is also a risk of reinforcing other biases and inequalities that are also critical to the scholarly dialogue on open science practices. The ultimate visibility of, and trust towards, scientific research by the general public matters for various stakeholders — yet adopting open science practices may bring additional challenges. 


\section{References}

Abele-Brehm, A. E., Gollwitzer, M., Steinberg, U., \& Schönbrodt, F. D. (2019). Attitudes toward open science and public data sharing. Social Psychology, 50, 252-260.

\section{https://doi.org/10.1027/1864-9335/a000384}

Abramo, G., D’Angelo, C., \& Di Costa, F. (2010). Citations versus journal impact factor as proxy of quality: Could the latter ever be preferable? Scientometrics, 84(3), 821-833. https://doi.org/10.1007/s11192-010-0200-1

Anvari, F., \& Lakens, D. (2018). The replicability crisis and public trust in psychological science. Comprehensive Results in Social Psychology, 3(3), 266-286.

\section{https://doi.org/10.1080/23743603.2019.1684822}

Aronow, P. M., Baron, J., \& Pinson, L. (2019). A note on dropping experimental subjects who fail a manipulation check. Political Analysis, 27(4), 572-589.

\section{https://doi.org/10.1017/pan.2019.5}

Baguley, T. (2009). Standardized or simple effect size: What should be reported? British Journal of Psychology, 100(3), 603-617. https://doi.org/10.1348/000712608X377117

Bahlai, C., Bartlett, L.J., Burgio, K.R. et al. (2019). Open science isn’t always open to all scientists. American Scientist, 107(2), 78. https://doi.org/10.1511/2019.107.2.78

Bakker, B. N., Jaidka, K., Dörr, T., Fasching, N., \& Lelkes, Y. (2020). Questionable and open research practices: attitudes and perceptions among quantitative communication researchers. Journal of Communication, 71(5), 715-738. https://doi.org/10.1093/joc/jqab031

Besançon, L., Peiffer-Smadja, N., Segalas, C., Jiang, H., Masuzzo, P., Smout, C., ... \& Leyrat, C. (2021). Open science saves lives: Lessons from the COVID-19 pandemic. BMC Medical Research Methodology, 21(1), 1-18. https://doi.org/10.1186/s12874-021$\underline{01304-y}$ 
Catling, J. C., Mason, V. L., \& Upton, D. (2009). Quality is in the eye of the beholder? An evaluation of impact factors and perception of journal prestige in the UK. Scientometrics, 81(2), 333-345. https://doi.org/10.1007/s11192-009-2124-1

Chan, C. H., \& Grill, C. (2020). The highs in communication research: Research topics with high supply, high popularity, and high prestige in high-impact journals. Communication Research, 0093650220944790. https://doi.org/10.1177/0093650220944790

Chakravartty, P., Kuo, R.., Grubbs, V., \& Mcllwain, C. (2018). \#CommunicationSoWhite. Journal of Communication, 68(2), 254-266. https://doi.org/10.1093/joc/jqy003

Clemens, E. S., Powell, W. W., McIlwaine, K., \& Okamoto, D. (1995). Careers in print: Books, journals, and scholarly reputations. American Journal of Sociology, 101(2), 433-494. https://doi.org/10.1086/230730

Coronel, J. C., O’Donnell, M. B., Pandey, P., Delli Carpini, M. X., \& Falk, E. B. (2021). Political humor, sharing, and remembering: Insights from Neuroimaging. Journal of Communication, 71(1), 129-161. https://doi.org/10.1093/joc/jqaa041

Critchley, C. R. (2008). Public opinion and trust in scientists: The role of the research context, and the perceived motivation of stem cell researchers. Public Understanding of Science, 17(3), 309-327. https://doi.org/10.1177/0963662506070162

Cummings, L. (2014). The "trust" heuristic: Arguments from authority in public health. Health Communication, 29(10), 1043-1056. https://doi.org/10.1080/10410236.2013.831685

Derksen, M., \& Field, S. M. (2021, April 18). The tone debate: knowledge, self, and social order. PsyArXiv. https://doi.org/10.31234/osf.io/g8nhu

Dienlin, T., Johannes, N., Bowman, N. D., Masur, P. K., Engesser, S., Kümpel, A. S., ... \& De Vreese, C. (2021). An agenda for open science in communication. Journal of Communication, 71(1), 1-26. https://doi.org/10.1093/joc/jqz052 
Field, S. M., Wagenmakers, E. J., Kiers, H. A., Hoekstra, R., Ernst, A. F., \& van Ravenzwaaij, D. (2020). The effect of preregistration on trust in empirical research findings: Results of a registered report. Royal Society Open Science, 7(4), 181351. https://doi.org/10.1098/rsos.181351

Fox, J., Pearce, K. E., Massanari, A. L., Riles, J. M., Szulc, Ł., Ranjit, Y. S., ... \& L Gonzales, A. (2021). Open science, closed doors? Countering marginalization through an agenda for ethical, inclusive research in communication. Journal of Communication. 71(5), 764-784. https://doi.org/10.1093/joc/jqab029

Freiling, I., Krause, N. M., Scheufele, D. A., \& Chen, K. (2021). The science of open (communication) science: Toward an evidence-driven understanding of quality criteria in communication research. Journal of Communication, 71(5), 686-714.

\section{https://doi.org/10.1093/joc/jqab032}

Grimes, D. R., Bauch, C. T., \& Ioannidis, J. P. (2018). Modelling science trustworthiness under publish or perish pressure. Royal Society Open Science, 5(1), 171511. https://doi.org/10.1098/rsos.171511

Hendriks, F., Kienhues, D., \& Bromme, R. (2015). Measuring laypeople's trust in experts in a digital age: The Muenster Epistemic Trustworthiness Inventory (METI). PloS one, 10(10), e0139309. https://doi.org/10.1371/journal.pone.0139309

Hendriks, F., Kienhues, D., \& Bromme, R. (2016). Disclose your flaws! Admission positively affects the perceived trustworthiness of an expert science blogger. Studies in Communication Sciences, 16(2), 124-131. https://doi.org/10.1016/j.scoms.2016.10.003

Hendriks, F., Kienhues, D., \& Bromme, R. (2020). Replication crisis = trust crisis? The effect of successful vs failed replications on laypeople's trust in researchers and research. Public Understanding of Science, 29(3), 270-288. https://doi.org/10.1177/0963662520902383 
Howard, D. (1994). Einstein, Kant, and the origins of logical empiricism. In W. C. Salmon \& G. Wolters (Eds.), Language, logic, and the structure of scientific theories (pp. 45-105). Pittsburgh, PA: University of Pittsburgh Press.

Ioannidis, J. P., Munafo, M. R., Fusar-Poli, P., Nosek, B. A., \& David, S. P. (2014). Publication and other reporting biases in cognitive sciences: Detection, prevalence, and prevention. Trends in Cognitive Sciences, 18(5), 235-241.

https://doi.org/10.1016/j.tics.2014.02.010

Kidwell, M. C., Lazarević, L. B., Baranski, E., Hardwicke, T. E., Piechowski, S., Falkenberg, L. S., ... \& Nosek, B. A. (2016). Badges to acknowledge open practices: A simple, lowcost, effective method for increasing transparency. PLoS biology, 14(5), e1002456. https://doi.org/10.1371/journal.pbio.1002456

Krause, N. M., Brossard, D., Scheufele, D. A., Xenos, M. A., \& Franke, K. (2019). TrendsAmericans' trust in science and scientists. Public Opinion Quarterly, 83(4), 817-836. https://doi.org/10.1093/poq/nfz041

Keating, D. M., \& Totzkay, D. (2019). We do publish (conceptual) replications (sometimes): Publication trends in communication science, 2007-2016. Annals of the International Communication Association, 43(3), 225-239.

https://doi.org/10.1080/23808985.2019.1632218

Kuhn, T. (1962). The structure of scientific revolutions. Chicago University Press.

Lewis, N. A., Jr. (2020). Open communication science: A primer on why and some recommendations for how. Communication Methods \& Measures, 14(2), 71-82. https://doi.org/10.1080/19312458.2019.1685660

Markowitz, D. M., Song, H., \& Taylor, S. H. (2021). Tracing the adoption and effects of open science in communication research. Journal of Communication, 71(5), 739-763. https://doi.org/10.1093/joc/jqab030 
Matthes, J., Marquart, F., Naderer, B., Arendt, F., Schmuck, D., \& Adam, K. (2015).

Questionable research practices in experimental communication research: A systematic analysis from 1980 to 2013. Communication Methods and Measures, 9(4), 193-207. https://doi.org/10.1080/19312458.2015.1096334

Maxwell, S. E., Lau, M. Y., \& Howard, G. S. (2015). Is psychology suffering from a replication crisis? What does "failure to replicate" really mean? American Psychologist, 70(6), 487. https://doi.org/10.1037/a0039400

McEwan, B., Carpenter, C. J., \& Westerman, D. (2018). On replication in communication science. Communication Studies, 69(3), 235-241.

\section{https://doi.org/10.1080/10510974.2018.1464938}

Mede, N. G., Schäfer, M. S., Ziegler, R., \& Weißkopf, M. (2021). The "replication crisis" in the public eye: Germans' awareness and perceptions of the (ir)reproducibility of scientific research. Public Understanding of Science, 30(1), 91-102.

\section{https://doi.org/10.1177/0963662520954370}

Merrill, A. F., \& Afifi, T. D. (2017). Couple identity gaps, the management of conflict, and biological and self-reported stress in romantic relationships. Human Communication Research, 43(3), 363-396. https://doi.org/10.1111/hcre.12110

Merton, R. K. (1957). Priorities in scientific discovery: A chapter in the sociology of science. American Sociological Review, 22(6), 635-659. https://doi.org/10.2307/2089193

Merton, R. K. (1968). The Matthew effect in science: The reward and communication systems of science are considered. Science, 159(3810), 56-63.

\section{https://doi.org/10.1126/science.159.3810.56}

Merton, R. K. (1973). The sociology of science: Theoretical and empirical investigations. Chicago, IL: University of Chicago press.

Miller, J. D. (2004). Public understanding of, and attitudes toward, scientific research: What 
we know and what we need to know. Public Understanding of Science, 13(3), 273-294. https://doi.org/10.1177/0963662504044908

Montgomery, J. M., Nyhan, B., \& Torres, M. (2018). How conditioning on posttreatment variables can ruin your experiment and what to do about it. American Journal of Political Science, 62(3), 760-775. https://doi.org/10.1111/ajps.12357

Mummolo, J., \& Peterson, E. (2019). Demand effects in survey experiments: An empirical assessment. American Political Science Review, 113(2), 517-529.

https://doi.org/10.1017/S0003055418000837

Nosek, B. A., Alter, G., Banks, G. C., Borsboom, D., Bowman, S. D., Breckler, S. J., ... \& Yarkoni, T. (2015). Promoting an open research culture. Science, 348(6242), 14221425. http://doi.org/10.1126/science.aab2374

Oliver, M. B., \& Raney, A. A. (2011). Entertainment as pleasurable and meaningful: Identifying hedonic and eudaimonic motivations for entertainment consumption. Journal of Communication, 61(5), 984-1004. https://doi.org/10.1111/j.14602466.2011.01585.x

Open Science Collaboration. (2015). Estimating the reproducibility of psychological science. Science, 349(6251). https://doi.org/10.1126/science.aac4716

Pashler, H., \& Wagenmakers, E. J. (2012). Editors' introduction to the special section on replicability in psychological science: A crisis of confidence? Perspectives on Psychological Science, 7(6), 528-530. https://doi.org/10.1177/1745691612465253

Pek, J., \& Flora, D. B. (2018). Reporting effect sizes in original psychological research: A discussion and tutorial. Psychological Methods, 23(2), 208. http://dx.doi.org/10.1037/met0000126

Pew Research Center (2017, September). Science news and information today. https://www.pewresearch.org/journalism/2017/09/20/science-news-and-information- 
today/

Pew Research Center (2019, August). Trust and mistrust in Americans'views of scientific experts. https://www.pewresearch.org/science/2019/08/02/trust-and-mistrust-inamericans-views-of-scientific-experts/

Resnik, D. B. (1998). The ethics of science: An introduction. New York: Routledge.

Resnik, D. B. (2011). Scientific research and the public trust. Science and Engineering Ethics, 17(3), 399-409. https://doi.org/10.1007/s11948-010-9210-x

Rights, J. D., \& Sterba, S. K. (2019). Quantifying explained variance in multilevel models: An integrative framework for defining R-squared measures. Psychological Methods, 24(3), 309. https://doi.org/10.1037/met0000184

Rosman, T., Bosnjak, M., Silber, H., Koßmann, J., \& Heycke, T. (2020). Preregistration: Open Science and the Public's Trust in Science. PsychArchives. https://doi.org/10.23668/PSYCHARCHIVES.4470

Sabeti, P. (2018, January). For better science, call off the revolutionaries. Boston Globe. https://www.bostonglobe.com/ideas/2018/01/21/for-better-science-call-off$\underline{\text { revolutionaries }}$

Schneider, J., Rosman, T., Kelava, A., \& Merk, S. (2020). (Re)building trust? Journals’ open science badges influence trust in scientists. PsychArchives. http://doi.org/10.23668/psycharchives.4976

Schneider, J., Rosman, T., Kelava, A., \& Merk, S. (2021). Do open science badges increase trust in scientists among undergraduates, scientists, and the public? PsyArXiv. https://doi.org/10.31234/osf.io/43ec2

Simmons, J. P., Nelson, L. D., \& Simonsohn, U. (2011). False-positive psychology: Undisclosed flexibility in data collection and analysis allows presenting anything as significant. Psychological Science, 22(11), 1359-1366. 


\section{https://doi.org/10.1177/0956797611417632}

Skurka, C., Niederdeppe, J., Romero-Canyas, R., \& Acup, D. (2018). Pathways of influence in emotional appeals: Benefits and tradeoffs of using fear or humor to promote climate change-related intentions and risk perceptions. Journal of Communication, 68(1), 169193. https://doi.org/10.1093/joc/jqx008

Soderberg, C. K., Errington, T. M., Schiavone, S. R., Bottesini, J., Thorn, F. S., Vazire, S., ... \& Nosek, B. A. (2021). Initial evidence of research quality of registered reports compared with the standard publishing model. Nature Human Behaviour, 5(8), 990997. https://doi.org/10.1038/s41562-021-01142-4

Song, H., Eberl, J. M., \& Eisele, O. (2020). Less fragmented than we thought? Toward clarification of a subdisciplinary linkage in communication science, 2010-2019. Journal of Communication, 70(3), 310-334. https://doi.org/10.1093/joc/jqaa009

Teevan, J. J. (1980). Journal prestige and quality of sociological articles. The American Sociologist, 109-112. https://www.jstor.org/stable/27702409

Waisbord, S. (2019). Communication: A post-discipline. John Wiley \& Sons.

Wells, G. L., \& Windschitl, P. D. (1999). Stimulus sampling and social psychological experimentation. Personality and Social Psychology Bulletin, 25(9), 1115-1125. https://doi.org/10.1177/01461672992512005

Wilholt, T. (2013). Epistemic trust in science. The British Journal for the Philosophy of Science, 64(2), 233-253. https://doi.org/10.1093/bjps/axs007

Wingen, T., Berkessel, J. B., \& Englich, B. (2020). No replication, no trust? How low replicability influences trust in psychology. Social Psychological and Personality Science, 11(4), 454-463. https://doi.org/10.1177/1948550619877412

Wirth, W., Hofer, M., \& Schramm, H. (2012). Beyond pleasure: Exploring the eudaimonic entertainment experience. Human Communication Research, 38(4), 406-428. 
https://doi.org/10.1111/j.1468-2958.2012.01434.x

Yarborough, M. (2014). Openness in science is key to keeping public trust. Nature News, 515(7527), 313. https://doi.org/10.1038/515313a 